\title{
Evaluation of scoring systems without endoscopic findings for predicting outcomes in patients with upper gastrointestinal bleeding
}

II-Gyu Ko' , Sung-Eun Kim', Bok Soon Chang ${ }^{2}$, Min Seob Kwak², Jin Young Yoon², Jae Myung Cha², Hyun Phil Shin'2, Joung II Lee², Sang Hyun Kim³ ${ }^{3}$ Jin Hee Han ${ }^{4}$ and Jung Won Jeon ${ }^{2 *}$

\begin{abstract}
Background: Risk scoring systems are used to evaluate patients with upper gastrointestinal bleeding (UGIB). We compared Glasgow-Blatchford score (GBS), modified GBS (mGBS), and Pre-endoscopy Rockall score (Pre-E RS) for immediate application without endoscopic findings in predicting the need of interventions and the 30-day mortality in patients with UGIB.

Methods: Patients who visited the emergency room with UGIB from January 2007 to June 2016 were included. GBS, mGBS, and Pre-E RS were obtained for all patients. The area under the receiver-operating characteristic curves (AUC) was used to assess the accuracy of the scoring systems to determine the need for interventions and 30-day mortality. Also, we investigated the potential cutoff scores for predicting 30-day mortality and the need for interventions.

Results: In predicting the need for interventions, GBS (AUC $=0.727$ ) and $m G B S$ (AUC $=0.733$ ) outperformed Pre-E RS (AUC $=0.564, P<0.0001$ ). In predicting 30-day mortality, Pre-E RS (AUC $=0.929)$ outperformed GBS (AUC $=0.664$, $P<0.0001)$ and $m G B S(A \cup C=0.652, P<0.0001$ ). Based on AUC analyses of sensitivities and specificities, the optimal cutoff mGBS and GBS for the need for interventions was 9 (70.71\% sensitivity, 89.35\% specificity) and 9 (73.57\% sensitivity, $82.90 \%$ specificity) respectively, and optimal cutoff Pre-E RS for 30-day mortality was 4 (88.0\% sensitivity, 97.52\% specificity).

Conclusions: GBS and mGBS are considered to be moderately accurate in making an early decision about the need of interventions in patients with UGIB. Pre-E RS is considered to be highly accurate in early detection of patients at high risk for 30-day mortality without endoscopic findings. In addition, we suggested potential cutoff scores to predict the need of interventions for GBS and mGBS, and 30-day mortality for Pre-E RS. Further studies are needed to confirm the clinical applicability of results.
\end{abstract}

Keywords: Upper gastrointestinal bleeding, Need of interventions, 30-day mortality, Prediction, Scoring system

\footnotetext{
* Correspondence: drglory@naver.com

${ }^{2}$ Department of Internal Medicine, Kyung Hee University Hospital at

Gangdong, College of Medicine, Kyung Hee University, 892 Dongnam-ro,

Gangdong-gu, Seoul 05278, South Korea

Full list of author information is available at the end of the article
} 


\section{Background}

Upper gastrointestinal bleeding (UGIB), a common medical emergency, is reported in the emergency room by $5 \%$ per year and accounts for $2 \sim 3 \%$ of hospitalization in developed countries [1]. Mortality for UGIB reportedly ranges from $2 \%$ to $15 \%$ and rebleeding is as high as $10-30 \%$ [2-4]. Therefore, proper stratification for patients with UGIB can help to identify candidates for interventions including blood transfusion, endoscopic treatment, and radiologic or surgical intervention. Moreover, this process helps to decrease the 30-day mortality.

The 2010 International consensus guidelines recommended early risk stratification using proven factors for the management of patients with UGIB [5]. The recent American College of Gastroenterology practice guidelines for managing patients with ulcer bleeding also recommended that a risk assessment be conducted to stratify patients into high and low risk categories, which may assist in initial decisions such as timing of endoscopy, time of discharge, and level of care [6]. Early risk stratification in the emergency department facilitates proper treatment as well as rapid and accurate triage. This is important for timely administration of lifesaving treatments to patients and for reducing high medical care costs.

Several scoring systems have been developed to evaluate patients with UGIB [7, 8]. Decisions about urgent endoscopy are important in the diagnosis and treatment for patients with UGIB. The Rockall score (RS) is not suitable for the decision about urgent endoscopy since it requires endoscopic results. Whereas, the Pre-endoscopy Rockall score (Pre-E RS) and the Glasgow-Blatchford score (GBS) are suitable because they require only clinical and laboratory data. Therefore, they could be applied immediately without endoscopic findings. In addition, a modified GBS (mGBS), which eliminated subjective criteria from GBS, has been introduced [9].

In this study, we determined the immediate applicability without endoscopic findings of the GBS, mGBS, and PreE RS systems in estimating the need for interventions and predicting the 30-day mortality in patients with UGIB. Also, we investigated the potential cutoff scores to predict the need of interventions and 30-day mortality in applicable scoring systems.

\section{Methods}

\section{Study population}

This is the retrospective study which was carried out at a single teaching center. The medical records were used to recognize patients who visited the emergency department with UGIB between January 2007 and June 2016.

Patients $>18$ years of age who visited the emergency department with symptoms and signs of UGIB from either variceal or nonvariceal source were involved in the study. Patients diagnosed with lower gastrointestinal bleeding were excluded. Patients stable enough for direct discharge from the emergency room had been recommended out-patient endoscopic examination within 2 days according to protocol; and patients who had not visited the hospital after discharge were excluded. All participations were informed of the study purpose and written consents were obtained following the requirements of the Institutional Review Board of Kyung Hee University Hospital at Gangdong. This study was approved by the Institutional Review Board of Kyung Hee University Hospital at Gangdong (KHNMC IRB 2016-07-026).

\section{Data collection}

One junior doctor reviewed each subject's hospital record including admission notes, discharge records, laboratory data, and endoscopic results to identify the presence of UGIB. Data on age, sex, medication use, drinking, smoking, pulse rate, blood pressure, physical exam findings, laboratory results, co-morbidities, and endoscopic results were collected from each patient. In addition, data concerning interventions including blood transfusion, endoscopic intervention, radiologic intervention, or surgery and 30-day mortality were collected.

\section{Treatment}

The high dose proton pump inhibitor (Pantoloc ${ }^{\oplus}$ Takeda $\mathrm{GmbH}$, Singen, Germany, $80 \mathrm{mg}$ bolus once then $40 \mathrm{mg}$ every $6 \mathrm{~h}$ ) was administered to all subjects with UGIB intravenously. The terlipressin (Glypressin ${ }^{\circledR}$ Ferring Pharmaceuticals, Saint-Prex, Switzerland, $2 \mathrm{mg}$ initially followed by $1 \mathrm{mg}$ every $4 \mathrm{~h}$ ) was administered to subjects who were considered to have variceal bleeding intravenously. Actions were taken for patients requiring interventions. Interventions is defined as medical or surgical procedures including as follows; blood transfusion, combination endoscopic hemostasis using dilute epinephrine injection plus second hemostasis modality (contact thermal, mechanical, or sclerosant), radiologic arterial embolization, or surgery. Endoscopic hemostasis was performed when Endoscopic findings were judged as Forrest classification Ia, Ib, or IIa, and radiologic intervention or surgery were performed when endoscopic hemostasis failed.

\section{Scoring systems}

The GBS, mGBS, and Pre-E RS were calculated for each patient, as previously described (Table 1) [7-10]. The mGBS includes only quantitative factors of the GBS, which are blood urea nitrogen, hemoglobin $(\mathrm{Hb})$, systolic blood pressure (SBP) and pulse. The Pre-E RS excludes endoscopic finding from RS. After the calculation of scoring systems involved in this study, Receiver-operating 
Table 1 Scoring systems involved in this study

\begin{tabular}{|c|c|c|c|}
\hline Scoring system & Clinical factors & Parameters & Score \\
\hline \multirow[t]{13}{*}{ mGBS } & Pulse & $\geq 100$ & 1 \\
\hline & \multirow{3}{*}{$\begin{array}{l}\text { Systolic blood } \\
\text { pressure }(\mathrm{mmHg})\end{array}$} & $100-109$ & 1 \\
\hline & & $90-99$ & 2 \\
\hline & & $<90$ & 3 \\
\hline & \multirow{4}{*}{$\begin{array}{l}\text { Blood urea nitrogen } \\
(\mathrm{mg} / \mathrm{dL})\end{array}$} & $19-22.3$ & 2 \\
\hline & & $22.4-27.9$ & 3 \\
\hline & & $28-69.9$ & 4 \\
\hline & & $\geq 70$ & 6 \\
\hline & \multirow{3}{*}{$\begin{array}{l}\text { Hemoglobin for male } \\
(\mathrm{g} / \mathrm{dL})\end{array}$} & $12-12.9$ & 1 \\
\hline & & 10-11.9 & 3 \\
\hline & & $<10$ & 6 \\
\hline & \multirow{2}{*}{$\begin{array}{l}\text { Hemoglobin for } \\
\text { female }(\mathrm{g} / \mathrm{dL})\end{array}$} & 10-11.9 & 1 \\
\hline & & $<10$ & 6 \\
\hline \multirow{4}{*}{$\begin{array}{l}\text { GBS (includes four } \\
\text { additional factors) }\end{array}$} & Hepatic disease & Present & 2 \\
\hline & Cardiac failure & Present & 2 \\
\hline & Melena & Present & 1 \\
\hline & Syncope & Present & 2 \\
\hline \multirow[t]{9}{*}{ Pre-E RS } & \multirow[t]{3}{*}{ Age } & $<60$ & 0 \\
\hline & & $60-79$ & 1 \\
\hline & & $\geq 80$ & 2 \\
\hline & Shock & absent & 0 \\
\hline & Heart rate & $>100$ & 1 \\
\hline & $\begin{array}{l}\text { Systolic blood } \\
\text { pressure }(\mathrm{mmHg})\end{array}$ & $<100$ & 2 \\
\hline & \multirow[t]{3}{*}{ Comorbidity } & Nil major & 0 \\
\hline & & $\begin{array}{l}\text { IHD, CHF, } \\
\text { other major }\end{array}$ & 2 \\
\hline & & $\begin{array}{l}\mathrm{RF}, \mathrm{HF} \\
\text { Malignancy }\end{array}$ & 3 \\
\hline
\end{tabular}

mGBS modified Glasgow-Blatchford score, GBS Glasgow-Blatchford score, Pre-E RS Pre-endoscopy Rockall score, IHD ischemic heart disease,

$C H F$ congestive heart failure, $R F$ renal failure, $H F$ hepatic failure

characteristic (ROC) curves were constructed to evaluate the accuracy of several scoring systems in predicting the need for interventions and 30-day mortality. In addition, based on the analyses for the area under the ROC (AUC), optimal cutoff levels for intervention and 30-day mortality were investigated.

\section{Statistical analyses}

Descriptive analyses were conducted using SPSS (version 21.0; SPSS Inc., Chicago, IL, USA). Categorical variables were expressed by number and percentage occurrence frequency. Receiver-operating characteristic (ROC) curves were conducted, and the area under the ROC curve (AUC) with a 95\% confidence interval was calculated with MedCalc (version 16.4.3, MedCalc, Mariakerke, Belgium). Estimates of sensitivity, specificity, positive predictive value, and negative predictive value with 95\% confidence intervals (CIs) were obtained for each scoring system, and the ability to predict the need for interventions and the 30-day mortality was compared with MedCalc (version 16.4.3) using the method described by DeLong et al. [11]. The significance level for all analyses was set at $p<0.05$.

\section{Results \\ Patient characteristics}

Table 2 shows the characteristics of subjects involved in the study. Of 590 patients, 215 (36.4\%) were female; 166 (28.1\%) were $\leq 60$ years old and 133 (22.5\%) were between 60 and 70 years of age. 337 patients (57.1\%) had heart disease involving ischemic heart disease and cardiac failure in terms of comorbidity. 41 patients (6.9\%) had liver disease including acute or chronic hepatitis and liver cirrhosis. The presenting symptoms were melena $(n=288,48.8 \%)$, hematemesis $(n=147,24.9 \%)$, hematochezia $(n=135,22.9 \%)$, and syncope $(n=20$, 3.4\%). 202 patients (34.2\%) were taking aspirin, 90 patients $(15.3 \%)$ were taking warfarin, and 26 patients (4.4\%) were taking non-steroidal anti-inflammatory drugs (NSAIDs). 449 patients (76.1\%) received blood transfusion. 441 patients $(74.8 \%)$ underwent gastroscopy within $24 \mathrm{~h}$ of presentation to the hospital. Gastroscopy was not performed in 2 patients because they were considered as low risk and unlikely to require endoscopic therapy. Endoscopic intervention and radiologic intervention were performed in 191 (32.4\%) and 13 (2.2\%) patients respectively, and any surgery to treat UGIB was not performed. The 30-day mortality was $4.2 \%(n=25)$. The averages of GBS, mGBS, and Pre-E RS were 10.0, 9.4, and 2.0, respectively.

\section{Endoscopic findings}

Table 3 lists the endoscopic findings of included patients. 235 patients (39.9\%) were diagnosed with gastric ulcer. Of them, 114 patients underwent endoscopic hemostatic procedures and 9 patients underwent radiologic intervention, trans-arterial embolization. 49 patients $(8.3 \%)$ were diagnosed with variceal bleeding and 31 patients of them underwent endoscopic variceal ligation or histoacryl injection. 38 patients (6.4\%) were diagnosed with duodenal ulcer. Of them, 16 patients underwent endoscopic hemostatic procedures and 1 patient underwent radiologic intervention. 23 patients (3.9\%) were diagnosed with Mallory-Weiss syndrome, and 8 patients of them underwent endoscopic intervention. 17 patients $(2.9 \%)$ were diagnosed with Dieulafoy lesion. Of them, 14 patients underwent endoscopic intervention, and 3 patients underwent radiologic intervention. UGIB by malignancy was detected in 25 patients (4.2\%) and 8 patients of them underwent endoscopic 
Table 2 Characteristics of included patients

\begin{tabular}{|c|c|c|}
\hline & $\begin{array}{l}\text { Patients } \\
(N=590)\end{array}$ & $\begin{array}{l}\text { Percentage } \\
(\%) \\
\end{array}$ \\
\hline \multicolumn{3}{|l|}{ Gender } \\
\hline Female & 215 & 36.4 \\
\hline \multicolumn{3}{|l|}{ Age } \\
\hline Less than 60 & 166 & 28.1 \\
\hline $60 \sim 79$ & 133 & 22.5 \\
\hline More than 80 & 291 & 49.3 \\
\hline \multicolumn{3}{|l|}{ History of disease } \\
\hline Liver disease & 41 & 6.9 \\
\hline Renal disease & 3 & 0.5 \\
\hline Heart disease & 337 & 57.1 \\
\hline Metastatic malignancy & 6 & 1 \\
\hline \multicolumn{3}{|l|}{ Presenting symptoms } \\
\hline Melena & 288 & 48.8 \\
\hline Hematemesis & 147 & 24.9 \\
\hline Hematochezia & 135 & 22.9 \\
\hline Syncope & 20 & 3.4 \\
\hline \multicolumn{3}{|l|}{ Medication } \\
\hline No & 272 & 46.1 \\
\hline $\begin{array}{l}\text { Aspirin or other antiplatelet such as } \\
\text { clopidogrel }\end{array}$ & 202 & 34.2 \\
\hline Warfarin and other anticoagulant & 90 & 15.3 \\
\hline NSAIDs & 26 & 4.4 \\
\hline \multicolumn{3}{|l|}{ Time for endoscopic examination } \\
\hline Less than $6 \mathrm{~h}$ & 233 & 39.5 \\
\hline $6 \sim 24 h$ & 208 & 35.3 \\
\hline $24 \sim 48 \mathrm{~h}$ & 143 & 24.2 \\
\hline After $48 \mathrm{~h}$ & 4 & 0.7 \\
\hline No endoscopy & 2 & 0.3 \\
\hline \multicolumn{3}{|l|}{ Transfusion } \\
\hline No & 141 & 23.9 \\
\hline Yes & 449 & 76.1 \\
\hline \multicolumn{3}{|l|}{ Hemostatic procedures } \\
\hline No & 386 & 65.4 \\
\hline Endoscopic intervention & 191 & 32.4 \\
\hline Radiologic intervention & 13 & 2.2 \\
\hline Surgery & 0 & 0 \\
\hline \multicolumn{3}{|l|}{ 30-day mortality } \\
\hline Survival & 565 & 95.8 \\
\hline Death & 25 & 4.2 \\
\hline
\end{tabular}

NSAIDs non-steroidal anti-inflammatory drugs

intervention. 12 patients (2\%), who showed normal finding in gastroscopy, were diagnosed with obscure gastrointestinal bleeding. They underwent capsule enteroscopy later. 89 patients $(15.1 \%)$ were diagnosed with gastritis,
Table 3 Endoscopic findings of included patients

\begin{tabular}{lll}
\hline & $\begin{array}{l}\text { Patients } \\
(I=590)\end{array}$ & $\begin{array}{l}\text { Percentage } \\
(\%)\end{array}$ \\
\hline Normal & 12 & 2 \\
Gastritis & 89 & 15.1 \\
Gastric ulcer & 235 & 39.9 \\
Esophagitis & 86 & 14.6 \\
Esophageal or fundic varix & 49 & 8.3 \\
Duodenitis & 1 & 0.2 \\
Duodenal ulcer & 38 & 6.4 \\
Portal gastropathy & 1 & 0.2 \\
Mallory Weiss syndrome & 23 & 3.9 \\
Malignancy & 25 & 4.2 \\
Dieulafoy lesion & 17 & 2.9 \\
Others & 12 & 2 \\
\hline Oher polyps 6 Schaki Ring Esophat & &
\end{tabular}

Others: polyps 6 Schatzki Ring 2 Esophageal diverticulum 4

which was considered to cause UGIB by mucosal hemorrhage. So they did not undergo endoscopic and radiologic interventions.

\section{The comparison of scoring systems for predicting the need of interventions and 30-day mortality without endoscopic findings}

Table 4 lists the patient numbers in each score and the patients numbers that underwent hemostatic interventions (transfusion and hemostatic procedures). Figure 1 presents the AUC of each scoring system for predicting the need of interventions and 30-day mortality. The GBS (AUC 0.727 [95\% CI 0.689-0.762]) and mGBS (AUC 0.733 [95\% CI 0.696-0.769]) outperformed the Pre-E RS (AUC $0.564 \quad[95 \%$ CI $0.696-0.769], p<0.0001$ ) in predicting the need of interventions. There was not the significant difference between GBS and mGBS in predicting this point. In predicting 30-day mortality, the Pre-E RS (AUC 0.929 [95\% CI 0.905-0.948]) outperformed the GBS (AUC 0.664 [95\% CI 0.624-0.702], $p<0.0001$ ) and mGBS (AUC 0.652 [95\% CI 0.612-0.691], $p<0.0001$ ).

Table 5 shows the ability to predict the need of interventions and 30-day mortality in applicable scoring systems. Based on AUC analyses of sensitivities and specificities in our study, the optimal cutoff mGBS and GBS to predict the need of interventions was 9 (70.71\% sensitivity, $89.35 \%$ specificity) and 9 (73.57\% sensitivity, $82.90 \%$ specificity) respectively. Of 397 patients with GBS > 9, 21 patients died in 30 day from presentation. Of them, 12 patients underwent endoscopy after $24 \mathrm{~h}$ from presentation, and 9 patients underwent endoscopy within $24 \mathrm{~h}\left(\mathrm{X}^{2}=21.675\right.$, $p<0.001)$. The odds ratio for 30 days mortality was 6.753 (95\% CI, 2.729 to 16.712 ) meaning that the probability of death in the endoscopy performance 
Table 4 The patient numbers in each score and the patients numbers that underwent hemostatic interventions (transfusion and hemostatic procedures)

\begin{tabular}{|c|c|c|c|}
\hline Score & $\begin{array}{l}\text { GBS } \\
\text { (Intervention } \mathrm{Y} / \mathrm{N} \text { ) }\end{array}$ & $\begin{array}{l}\text { mGBS } \\
\text { (Intervention } \mathrm{Y} / \mathrm{N} \text { ) }\end{array}$ & $\begin{array}{l}\text { Pre-E RS } \\
\text { (Intervention Y/N) }\end{array}$ \\
\hline 0 & - & - & $70(Y=24 / N=46)$ \\
\hline 1 & - & - & $96(Y=80 / N=16)$ \\
\hline 2 & - & - & $311(Y=77 / N=234)$ \\
\hline 3 & - & - & $38(Y=29 / N=9)$ \\
\hline 4 & - & - & $39(Y=35 / N=4)$ \\
\hline 5 & $2(Y=1 / N=1)$ & $3(Y=1 / N=2)$ & $22(Y=22 / N=0)$ \\
\hline 6 & $67(Y=27 / N=40)$ & $68(Y=28 / N=40)$ & $1(Y=1 / N=0)$ \\
\hline 7 & $41(Y=26 / N=15)$ & $41(Y=27 / N=14)$ & $13(Y=12 / N=1)$ \\
\hline 8 & $11(Y=9 / N=2)$ & $25(Y=12 / N=13)$ & - \\
\hline 9 & $70(Y=4 / N=55)$ & $79(Y=5 / N=74)$ & - \\
\hline 10 & $86(Y=21 / N=65)$ & $87(Y=33 / N=54)$ & - \\
\hline 11 & $44(Y=34 / N=10)$ & $54(Y=52 / N=2)$ & - \\
\hline 12 & $57(Y=19 / N=38)$ & $72(Y=4 / N=68)$ & - \\
\hline 13 & $96(Y=55 / N=41)$ & $122(Y=80 / N=42)$ & - \\
\hline 14 & $43(Y=13 / N=30)$ & $20(Y=19 / N=1)$ & - \\
\hline 15 & $32(Y=31 / N=1)$ & $17(Y=17 / N=0)$ & - \\
\hline 16 & $7(Y=6 / N=1)$ & $2(Y=2 / N=0)$ & - \\
\hline 17 & $31(Y=31 / N=0)$ & - & - \\
\hline 18 & $3(Y=3 / N=0)$ & - & - \\
\hline Total & 590 & 590 & 590 \\
\hline
\end{tabular}

Intervention Y: Number of patients using endoscopic intervention, radiologic intervention, surgery, and transfusion. Intervention $\mathrm{N}$ : Number of patient using only medication. GBS: Glasgow-Blatchford score, mGBS: modified GlasgowBlatchford score, Pre-E RS: Pre-endoscopy Rockall score

over $24 \mathrm{~h}$ was 6.753 times higher than in the endoscopy performance within $24 \mathrm{~h}$.

Of 372 patients with $\mathrm{mGBS}>9,21$ patients died in 30 day from presentation. Among them, 12 patients underwent endoscopy after $24 \mathrm{~h}$ from presentation, and 9 patients underwent endoscopy within $24 \mathrm{~h}\left(\mathrm{X}^{2}=\right.$
19.380, $p<0.001)$. The odds ratio for 30 days mortality was 6.215 (95\% CI, 2.510 to 15.390$)$ meaning that the probability of death in the endoscopy performance over $24 \mathrm{~h}$ was 6.215 times higher than in the endoscopy performance within $24 \mathrm{~h}$. In addition, based on AUC analyses of sensitivities and specificities in our study, the optimal cutoff Pre-E RS to predict 30-day mortality was 4 (88.0\% sensitivity, $97.52 \%$ specificity).

\section{Discussion}

In our study, the rate of subjects who received blood transfusion $(76.1 \%)$ was higher compared with previously published studies [12, 13], because the rate of patients who showed hemoglobin under $8 \mathrm{~g} / \mathrm{dL}$ was higher. On the other hand, 30-day mortality in our study was $4.2 \%$, which was lower than that of previous report by Laursen et al. [12]. The reason of this difference was considered that the rate of UGIB caused by malignancy was lower in the present study. The other characteristics of patients such as the rate of patients who underwent endoscopic or radiologic interventions were consistent with the previous study [12].

Lin et al. [14] reported that cyclooxygenase-2 selective inhibitors (coxibs) significantly increased the incidence of UGIB, and various risk factors, including age, male gender, history of uncomplicated peptic ulcer disease, peptic ulcer bleeding, and H. pylori infection, contributed to the development of UGIB in coxibs users. The use of non-steroidal anti-inflammatory agents (NSAIDs) and anticoagulation agents associated with aging was considered to increase the development of UGIB by peptic ulcer. In our study, peptic ulcer disease including gastric ulcer and duodenal ulcer was the most common cause of UGIB, and $19.7 \%$ of patients took NSAIDs and anticoagulation agents. In our endoscopic findings, $2 \%$ of patients showing normal gastroscopic and colonoscopic findings were diagnosed with obscure gastrointestinal (GI) bleeding which is defined as persisting and/or

\section{a ROC curves for comparison (Intervention)}

\section{b ROC curves for comparison (30-day Mortality)}
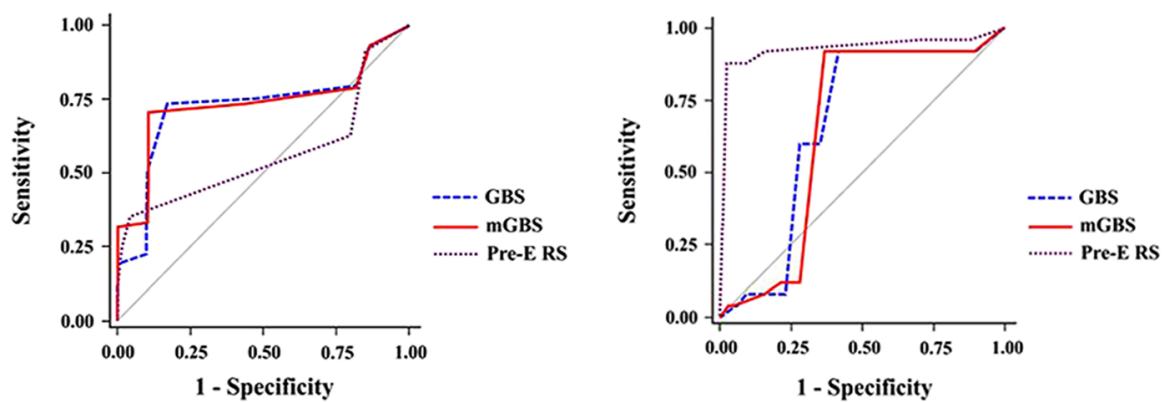

Fig. 1 Comparisons of the GBS, mGBS, and Pre-E RS using AUC of each scoring system. a The need of interventions (blood transfusion, endoscopic, radiologic or surgical intervention). b 30-day mortality. ROC: Receiver-operating characteristic, AUC: Area under the receiver-operating characteristic curves, GBS: Glagow-Blatchford Score, mGBS: modified Glagow-Blatchford Score, Pre-E RS: Pre-Endoscopy Rockall score 
Table 5 Ability to predict need of interventions and 30-day mortality

\begin{tabular}{|c|c|c|c|c|c|c|}
\hline Outcomes & System & Cutoff & Sensitivity, \% & Specificity, \% & PPV, \% & NPV, \% \\
\hline \multirow[t]{14}{*}{ Interventions } & GBS & $>6$ & 93.21 & 13.23 & 49.2 & 68.3 \\
\hline & GBS & $>7$ & 79.64 & 18.06 & 46.8 & 49.6 \\
\hline & GBS & $>8$ & 75.36 & 52.26 & 58.8 & 70.1 \\
\hline & GBS & $>9$ & 73.57 & 82.90 & 79.5 & 77.6 \\
\hline & GBS & $>10$ & 61.43 & 86.45 & 80.4 & 71.3 \\
\hline & GBS & $>11$ & 50.71 & 89.68 & 81.6 & 66.8 \\
\hline & GBS & $>12$ & 36.07 & 90.00 & 76.5 & 60.9 \\
\hline & mGBS & $>6$ & 92.86 & 13.55 & 49.2 & 67.7 \\
\hline & mGBS & $>7$ & 78.93 & 18.06 & 46.5 & 48.7 \\
\hline & mGBS & $>8$ & 73.57 & 55.81 & 60.1 & 70.0 \\
\hline & $\mathrm{mGBS}$ & $>9$ & 70.71 & 89.35 & 85.7 & 77.2 \\
\hline & $\mathrm{mGBS}$ & $>10$ & 46.07 & 89.35 & 79.6 & 64.7 \\
\hline & $\mathrm{mGBS}$ & $>11$ & 33.21 & 89.68 & 74.4 & 59.8 \\
\hline & mGBS & $>12$ & 31.79 & 99.68 & 98.9 & 61.8 \\
\hline \multirow[t]{5}{*}{ 30-day mortality } & Pre-E RS & $>2$ & 92.0 & 84.07 & 20.4 & 99.6 \\
\hline & Pre-E RS & $>3$ & 88.0 & 90.62 & 29.3 & 99.4 \\
\hline & Pre-E RS & $>4$ & 88.0 & 97.52 & 61.1 & 99.5 \\
\hline & Pre-E RS & $>5$ & 32.0 & 98.94 & 57.1 & 97.0 \\
\hline & Pre-E RS & $>6$ & 32.0 & 99.12 & 61.5 & 97.1 \\
\hline
\end{tabular}

PPV positive predictive value, NPV negative predictive value, GBS Glagow Blatchford Score, mGBS modified Glagow Blatchford Score, Pre-E RS Pre-Endoscopy Rockall score

recurrent GI bleeding of unidentified source after negative bidirectional endoscopic evaluation [15]. In case of obscure GI bleeding, we conducted capsule enteroscopy that is considered to be safe and effective for diagnosis of obscure GI bleeding [16].

Laine et al. [17] reported that patients who present with 6 to $12 \mathrm{~h}$ of the onset of UGIB symptoms show a significantly lower risk for transfusion owing to the higher hemoglobin level at presentation. On the other hand, patients delaying their presentation are more likely to have anemia, which increase transfusion requirement [17]. In the present study, we did not classify our study population according to time to presenation (rapid or delayed). Fortunately, Laine et al. [17] suggested that there is no apparent relationship between bleeding severity and time to presentation because there were no differences in mortality and requirement of hemostatic intervention with endoscopy, surgery or radiology among patients with rapid and delayed presentation.

When we planned this study, we considered a research involving only patients with non-variceal bleeding. However patients with symptoms and signs of UGIB who visited emergency department could not be distinguished clearly between variceal bleeding and nonvariceal bleeding first. So, we analyzed patients with symptoms and signs of UGIB from either variceal or non-variceal source. However, when we analyzed data involving only patients with non-variceal bleeding, the result was similar with that of this study.

Several risk scoring systems have been produced to divide patients with UGIB into high- and low-risk categories. 2010 international consensus for UGIB recommended that the use of prognostic scales was needed for early stratification of patients with UGIB according to the degree of risk [5]. Early identification of patients who are likely to show the need of interventions or high mortality could improve efficiency of care. However, RS is not suitable for an early decision on need of urgent interventions in the management of patients with UGIB, since it requires endoscopic finding. For this reason, we compared 3 scoring systems (GBS, mGBS, and Pre-E RS) that could be applied immediately without endoscopic findings.

In this study, we used AUC to evaluate the 3 scoring systems for predicting the need of interventions and 30day mortality in patients with UGIB. An arbitrary guideline proposed by Swets classifies scoring systems as noninformative (AUC $=0.5$ ), less accurate $(0.5<\mathrm{AUC} \leq 0.7)$, moderately accurate $(0.7<\mathrm{AUC} \leq 0.9)$, highly accurate $(0.9<\mathrm{AUC}<1)$ and perfect tests $(\mathrm{AUC}=1)$ [18]. AUC analyses in this study indicated that GBS and mGBS were moderately accurate (AUC $=0.727$ and 0.733, respectively) and superior to Pre-E RS (AUC $=0.564$ ) in predicting the need of interventions without endoscopic 
findings, consistent with prior studies. Cheng et al. [9] prospectively evaluated 199 patients with UGIB. They reported that $\mathrm{mGBS}(\mathrm{AUC}=0.85)$ performed as well as the GBS ( $\mathrm{AUC}=0.86, p=0.81$ ), and outperformed the Pre-E RS (AUC $=0.66, p<0.0001$ ) in predicting the need of interventions. Stanley et al. [19] reported that GBS was superior to Pre-E RS in predicting the need of interventions in a prospective study on 1555 subjects. On the other hand, the Pre-E RS is reported to be superior to GBS in predicting mortality of patients with UGIB [20]. Similarly, our study also showed that Pre-E RS outperformed GBS and mGBS in prediciting 30-day mortality. Many studies have reported that the RS was more closely associated with the probability of death than the chance of rebleeding [8, 21, 22]. Rockall et al. [23] reported that the RS was originally developed to predict the mortality rather than the prediction of rebleeding. The RS without endoscopy can identify the patients who are less likely to require intensive health care, and be used for endoscopic evaluation as outpatients, which improves the quality of patients' care and allows substantial resource savings [24].

A recent retrospective study proposed that early gastroscopy should be performed for high-risk patients with GBS $>12$ to reduce mortality [25]. Our study indicated that the risk of significant bleeding to need interventions increased in patients with GBS $>9$ or $\mathrm{mGBS}>9$. Our results suggest that patients with GBS $>9$ or $\mathrm{mGBS}>9$ need hemostatic interventions and have to undergo early gastroscopy. Collectively, these findings advocate guidelines for early gastroscopy in high-risk patients with UGIB, which allow risk stratification and provision of appropriate endoscopic treatment [5]. Previous study showed that $\mathrm{RS}<2$ was indicative of low risk of mortality [10]. In our study, patients with Pre-RS $>4$ showed high 30-day mortality, indicating that patients with PreRS $>4$ should be managed with more immediate and intensive care to lower 30-day mortality. However, large prospective trials are needed for further evaluation of cutoff values.

This is the large-scale retrospective study to propose an appropriate scoring system without endoscopic findings for predicting the need of interventions and 30day mortality in patients with UGIB. Our results may be useful to physicians in the emergency department for early decisions on interventions and prognosis. However, our study had some limitations. First, this was a singlecenter study from a teaching hospital, hence, our results cannot be generalized to all patients with the symptoms of UGIB. Second, there are generally some biases affecting the veracity of the retrospective study, such as selection bias, information bias and confounding, although all medical records used in this study were reviewed and entered into a database by one medical doctor for the quality of data. Finally, the rate of high-risk patients presenting with the symptoms of UGIB was high in this study. Therefore, further studies are required for accurate clinical applicability of results.

\section{Conclusions}

The GBS and mGBS are considered to be moderately accurate with good sensitivity and specificity in making an early decision about the need of interventions in patients with UGIB. Pre-E RS is considered to be highly accurate in early detection of patients at high risk for 30-day mortality without endoscopic findings. In addition, we suggested potential cutoff scores to predict the need of interventions in GBS and mGBS and 30-day mortality in Pre-E RS. These risk scoring systems predicting the need of intervention and/or 30-day mortality can contribute to saving lives and alleviating the severity of a patient's condition. Especially, these scores may be useful in case of emergency where endoscopy are not available. In this sense, the verification of risk scoring systems through the substantial clinical data conducted in this study may be beneficial to both physicians and patients. However, the perfect score should be applicable in pre- and post-endoscopy. Further studies are needed to confirm the clinical applicability of results.

\section{Abbreviations \\ AUC: Area under the receiver-operating characteristic curves; Cis: Confidence intervals; COX-2: Cyclooxygenase-2; Coxibs: cyclooxygenase-2 selective inhibitors; GBS: Glasgow-Blatchford score; Gl: Gastrointestinal; \\ $\mathrm{Hb}$ : hemoglobin; mGBS: modified GBS; NSAIDs: Non-steroidal anti- inflammatory agents; Pre-E RS: Pre-endoscopy Rockall score; ROC: Receiver- operating characteristic; RS: Rockall score; SBP: Systolic blood pressure; UGIB: Upper gastrointestinal bleeding}

\section{Acknowledgements}

Not applicable.

Funding

The study received no funding.

Availability of data and materials

The datasets used and/or analyzed during the current study are available from the corresponding author on reasonable request.

\section{Authors' contributions}

JW, IG, and SE participated in the design of the study, data collection, interpreted the data, and drafted the manuscript. BS and MS contributed to the design of the study, interpreted and analyzed the data and reviewed the manuscript. $J, J H$, and SH participated in the design of the study, data collection and involved in drafting the manuscript. JY, JM, and HP participated in the design of the study, interpreted the data, drafted and edited the manuscript. All authors gave final approval of the final version of the manuscript to be published, and all are agree to be accountable to all aspects of the work.

\section{Ethics approval and consent to participate}

All participations were informed of the study purpose and written consents were obtained following the requirements of the Institutional Review Board of Kyung Hee University Hospital at Gangdong. The Institutional Review Board of Kyung Hee University Hospital at Gangdong (KHNMC IRB 2016-07-026) reviewed and approved this study. 


\section{Consents for publication}

Not applicable.

\section{Competing interests}

The authors declare that they have no competing interests.

\section{Publisher's Note}

Springer Nature remains neutral with regard to jurisdictional claims in published maps and institutional affiliations.

\section{Author details}

'Department of Physiology, College of Medicine, Kyung Hee University, Seoul 02447, South Korea. ${ }^{2}$ Department of Internal Medicine, Kyung Hee University Hospital at Gangdong, College of Medicine, Kyung Hee University, 892 Dongnam-ro, Gangdong-gu, Seoul 05278, South Korea. ${ }^{3}$ Department of Surgery, Kyung Hee University Hospital at Gangdong, College of Medicine, Kyung Hee University, Seoul 05278, South Korea. ${ }^{4}$ Department of Anesthesiology and Pain Medicine, College of Medicine, Kyung Hee University, Seoul 02447, South Korea.

Received: 16 August 2017 Accepted: 28 November 2017

Published online: 12 December 2017

\section{References}

1. Hearnshaw SA, Logan RF, Lowe D, Travis SP, Murphy MF, Palmer KR. Acute upper gastrointestinal bleeding in the UK: patient characteristics, diagnoses and outcomes in the 2007 UK audit. Gut. 2011;60:1327-35.

2. Laine L, Peterson WL. Bleeding peptic ulcer. N Engl J Med. 1994;331:717-27.

3. Katschinski B, Logan R, Davies J, Faulkner G, Pearson J, Langman M. Prognostic factors in upper gastrointestinal bleeding. Dig Dis Sci. 1994;39:706-12.

4. van Leerdam ME, Vreeburg EM, Rauws EA, Geraedts AA, Tijssen JG, Reitsma JB, Tytgat GN. Acute upper Gl bleeding: did anything change? Time trend analysis of incidence and outcome of acute upper $\mathrm{Gl}$ bleeding between 1993/1994 and 2000. Am J Gastroenterol. 2003;98:1494-9.

5. Barkun AN, Bardou M, Kuipers EJ, Sung J, Hunt RH, Martel M, Sinclair P. International consensus upper gastrointestinal bleeding conference group. International consensus recommendations on the management of patients with nonvariceal upper gastrointestinal bleeding. Ann Intern Med. 2010;152:101-13.

6. Laine $L$, Jensen DM. Management of patients with ulcer bleeding. Am J Gastroenterol. 2012;107:345-60.

7. Blatchford O, Murray WR, Blatchford MA. Risk score to predict need for treatment for upper-gastrointestinal haemorrhage. Lancet. 2000;356:1318-21.

8. Vreeburg EM, Terwee CB, Snel P, Rauws EA, Bartelsman JF, Meulen JH, Tytgat GN. Validation of the Rockall risk scoring system in upper gastrointestinal bleeding. Gut. 1999:44:331-5.

9. Cheng DW, YW L, Teller T, Sekhon HK, Wu BUA. Modified Glasgow Blatchford score improves risk stratification in upper gastrointestinal bleed: a prospective comparison of scoring systems. Aliment Pharmacol Ther. 2012;36:782-9.

10. Ch'ng CL, Kingham JG. Scoring systems and risk assessment for upper gastrointestinal bleeding. Eur J Gastroenterol Hepatol. 2001;13:1137-9.

11. DeLong ER, DeLong DM, Clarke-Pearson DL. Comparing the areas under two or more correlated receiver operating characteristic curves: a nonparametric approach. Biometrics. 1988:44:837-45.

12. Laursen SB, Hansen JM, Schaffalitzky de Muckadell OB. The Glasgow Blatchford score is the most accurate assessment of patients with upper gastrointestinal hemorrhage. Clin Gastroenterol Hepatol. 2012;10:1130-5.

13. Laursen SB, Dalton HR, Murray IA, et al. Performance of new thresholds of the Glasgow Blatchford score in managing patients with upper gastrointestinal bleeding. Clin Gastroenterol Hepatol. 2015;13:115-21.

14. Lin XH, Young SH, Luo JC, Peng YL, Chen PH, Lin CC, Chen WM, Hou MC, Lee FY. Risk factors for upper gastrointestinal bleeding in patients taking selective COX-2 inhibitors: a Nationwide population-based cohort study. Pain Med. 2017;28:1-7.

15. ASGE Standards Of practice committee, Gurudu SR, Bruining DH, Acosta RD, Eloubeidi MA, Faulx AL, Khashab MA, Kothari S, Lightdale JR, Muthusamy VR, Yang J, JM DW. The role of endoscopy in the management of suspected small-bowel bleeding. Gastrointest Endosc. 2017;85:22-31.
16. Magnano A, Privitera A, Calogero G, Nanfitò L, Sanfilippo G, Biondi A, Basile F. The role of capsule endoscopy in the work-up of obscure gastrointestinal bleeding. Eur J Gastroenterol Hepatol. 2004;16:403-6.

17. Laine L, Laursen SB, Dalton HR, Ngu JH, Schultz M, Stanley AJ. Relationship of time to presentation after onset of upper Gl bleeding with patient characteristics and outcomes: a prospective study. Gastrointest Endosc. 2017:7:S516-20.

18. Swets JA. Measuring the accuracy of diagnostic systems. Science. 1988;240: 1285-93.

19. Stanley AJ, Dalton HR, Blatchford O, Ashley D, Mowat C, Cahill A, Gaya DR, Thompson E, Warshow U, Hare N, Groome M, Benson G, Murray W. Multicentre comparison of the Glasgow Blatchford and Rockall scores in the prediction of clinical end-points after upper gastrointestinal haemorrhage. Aliment Pharmacol Ther. 2011;34:470-5

20. Yang HM, Jeon SW, Jung JT, Lee DW, Ha CY, Park KS, Lee SH, Yang CH, Park $J \mathrm{H}$, Park YS. Comparison of scoring systems for nonvariceal upper gastrointestinal bleeding: a multicenter prospective cohort study. J Gastroenterol Hepatol. 2016;31:119-25.

21. Chen IC, Hung MS, Chiu TF, Chen JC, Hsiao CT. Risk scoring systems to predict need for clinical intervention for patients with nonvariceal upper gastrointestinal tract bleeding. Am J Emerg Med. 2007;25:774-9.

22. Bessa X, O'Callaghan $E$, Ballesté B, Nieto M, Seoane A, Panadès A, Vazquez DJ, Andreu M, Bory F. Applicability of the Rockall score in patients undergoing endoscopic therapy for upper gastrointestinal bleeding. Dig Liver Dis. 2006:38:12-7.

23. Rockall TA, Logan RF, Devlin HB, Northfield TC. Risk assessment after acute upper gastrointestinal haemorrhage. Gut. 1996;38:316-21.

24. Monteiro S, Gonçalves TC, Magalhães J, Cotter J. Upper gastrointestinal bleeding risk scores: who, when and why? World J Gastrointest Pathophysiol. 2016;7:86-96.

25. Lim LG, Ho KY, Chan YH, Teoh PL, Khor CJ, Lim LL, Rajnakova A, Ong TZ, Yeoh KG. Urgent endoscopy is associated with lower mortality in high-risk but not low-risk nonvariceal upper gastrointestinal bleeding. Endoscopy. 2011;43:300-6.

\section{Submit your next manuscript to BioMed Central and we will help you at every step:}

- We accept pre-submission inquiries

- Our selector tool helps you to find the most relevant journal

- We provide round the clock customer support

- Convenient online submission

- Thorough peer review

- Inclusion in PubMed and all major indexing services

- Maximum visibility for your research

Submit your manuscript at www.biomedcentral.com/submit
Biomed Central 